\title{
A detailed immunohistochemical analysis of the PI3K/AKT/mTOR pathway in lung cancer: Correlation with PIK3CA, AKT1, K-RAS or PTEN mutational status and clinicopathological features
}

\author{
ELENI ANDRIANA TRIGKA ${ }^{1 *}$, GEORGIA LEVIDOU $^{1 *}$, ANGELICA A. SAETTA $^{1 *}$, ILENIA CHATZIANDREOU $^{1}$, \\ PERIKLIS TOMOS $^{2}$, NIKOLAOS THALASSINOS ${ }^{3}$, NIKOLAOS ANASTASIOU ${ }^{3}$, ELEFTHERIOS SPARTALIS ${ }^{2}$, \\ NIKOLAOS KAVANTZAS ${ }^{1}$, EFSTRATIOS PATSOURIS ${ }^{1}$ and PENELOPE KORKOLOPOULOU ${ }^{1}$ \\ ${ }^{1}$ First Department of Pathology and ${ }^{2}$ Second Department of Propaedeutic Surgery, University of Athens Medical School, \\ Laiko General Hospital, 11527 Athens; ${ }^{3}$ Department of Thoracic Surgery, 1st IKA Hospital, 15127 Athens, Greece
}

Received January 9, 2013; Accepted February 8, 2013

DOI: $10.3892 /$ or.2013.2512

\begin{abstract}
The phosphoinositide 3-kinase (PI3K)/v-akt murine thymoma viral oncogene homolog (AKT)/mammalian target of rapamycin (mTOR) pathway is upregulated in a number of human cancers, including non-small cell lung cancer (NSCLC). Its potential role in NSCLC progression provides an attractive target for anticancer therapy. The expression of phosphorylated mTOR (p-mTOR), phosphorylated AKT (p-AKT), p85 $\alpha$ and p110 $\gamma$ subunits of PI3K, phosphorylated p70S6K (p-p70S6K), phosphatase and tensin homolog (PTEN) and phosphorylated 4E-BP1 (p-4E-BP1) was examined by immunohistochemistry in 102 NSCLC specimens. The results were correlated with clinicopathological features. We also examined 61 of our cases for the presence of PIK3CA, AKTI, PTEN and K-RAS mutations. A common PIK3CA mutation was detected at exon 9 in 2 samples (p.E545K), whereas another sample displayed a rare mutation (p.D1018N). Furthermore, 10 out of 54 cases (18.5\%) had a $K-R A S$ mutation at codon 12,5 had a PTEN mutation (exons 7 and 8) and 1 case had an $A K T 1$ mutation (p.E17K). $P T E N$ mutations were associated with nodal metastases. The expression of p-mTOR positively correlated with that of p-AKT and p-p70S6K and was higher in adenocarcinomas along with nuclear p110 $\gamma \mathrm{PI} 3 \mathrm{~K}$ expression, whereas $\mathrm{p}-4 \mathrm{E}-\mathrm{BP} 1$ expression was higher in squamous cell carcinomas. We also established a positive association between $\mathrm{p} 85 \alpha \mathrm{PI} 3 \mathrm{~K}$ or $\mathrm{p} 110 \gamma \mathrm{PI} 3 \mathrm{~K}$ and cytoplasmic p-AKT and its downstream effectors. An inverse correlation was noted between p-4E-BP1 immunoexpression and tumour status and nuclear p-AKT expression as regards
\end{abstract}

Correspondence to: Dr Georgia Levidou, First Department of Pathology, University of Athens Medical School, Laiko General Hospital, 75 Mikras Asias Street, 11527 Athens, Greece

E-mail: glevidou@yahoo.gr

${ }^{*}$ Contributed equally

Key words: PI3K/AKT/mTOR pathway, immunohistochemistry, non-small cell lung cancer, PIK3CA, AKT1, PTEN, K-RAS tumour stage. Univariate survival analysis demonstrated that p-4E-BP1 expression, either alone or in combination with cytoplasmic p-AKT expression had an adverse prognostic significance in adenocarcinomas. The combination of $\mathrm{p}-4 \mathrm{E}-\mathrm{BP} 1$ and cytoplasmic p-AKT expression remained significant in the multivariate analysis as a function of their interaction with histological type. Our data demonstrate the significance of p-4E-BP1 immunoexpression as a molecular marker of prognostic value in adenocarcinomas, particularly when combined with p-AKT.

\section{Introduction}

Lung cancer ranks highly among the leading causes of cancerrelated mortality worldwide, with non-small cell lung cancer (NSCLC) accounting for $\sim 75-85 \%$ of all lung malignancies (1). Despite significant advances in oncology research, 5-year survival rate of NSCLC does not exceed $16 \%$ (2). Gaining insight into the complex molecular mechanisms underlying the pathogenesis of NSCLC is essential for the identification of prognostic and predictive biological markers that may be targeted to improve clinical outcome.

The phosphoinositide 3-kinase (PI3K)/v-akt murine thymoma viral oncogene homolog (AKT)/mammalian target of rapamycin (mTOR) signalling pathway is emerging as a common theme in human carcinogenesis. mTOR coordinates basic cellular functions including cellular growth and proliferation (3). The aberrant activation of the pathway presents as either gain of growth-promoting function or loss of inhibitory function, facilitating neoplastic transformation. The engagement of receptor tyrosine kinases (RTKs) [epidermal growth factor receptor (EGFR), fibroblast growth factor receptor (FGFR), insulin-like growth factor-I receptor (IGF-IR) and platelet-derived growth factor receptor (PDGFR)], as well as Ras activate PI3K, thus leading to the generation of phosphatidylinositol triphosphate (PIP3) and in turn to the recruitment of AKT into the cell membrane for phosphorylation at threonine (Thr)308 and serine (Ser)473 (4). Once activated, AKT moves into the cytoplasm and the nucleus, where it phosphorylates, activates, or inhibits a number of downstream targets, regulating various cellular functions including cellular metabolism, 
protein synthesis, cell survival/inhibition of apoptosis and cell cycle progression. Among the various signalling cascades emanating from AKT, mTOR functions prominently as a critical downstream effector. mTOR is a serine/threonine kinase existing in 2 functionally distinct complexes-mTORC1 and mTORC2 (5). mTORC1 is sensitive to rapamycin and constitutes a major regulator of ribosomal biogenesis and protein synthesis, through the activation of the promoter of mRNA translation, S6K, and inactivation of the repressor of mRNA translation, 4E-BP1 (6). The phosphorylation of 4E-BP1 disrupts its interaction with eIF4E, allowing it to interact with eIF4G and form the eIF4F complex that enhances the overall translational machinery of the cell (7). mTORC2 is insensitive to rapamycin, phosphorylates AKT and regulates cell survival, migration and the actin cytoskeleton. Hence, mTORC1 and mTORC2 have different physiological functions (8). mTORC1 can be phosphorylated and activated by AKT directly or indirectly through the phosphorylation and subsequent inactivation of tuberous sclerosis complex 2 (TSC2) (9).

$\mathrm{PI} 3 \mathrm{~K}$ proteins, of which PI3Ka is the most relevant in the context of cancer, are heterodimers, consisting of a p110 catalytic subunit and a p85 regulatory subunit, which in the basal state, restricts the activity of the catalytic subunit (9). Oncogenic mutations of PIK3CA disrupt the inhibitory function of the p85 subunit, resulting in the unrestricted constitutive activity of p110 (10) with the consequent upregulation of PI3K/AKT signalling and are commonly encountered in human cancers. In NSCLC however, such mutations are uncommon $(11,12)$. The aberrant activation of PI3K may also be secondary to the loss-of-function gene alterations of phosphatase and tensin homolog (PTEN) (13). PTEN antagonises the ability of PI3K to phosphorylate AKT by removing phosphates at position 3 of PIP3, thereby serving as a tumour suppressor (14).

The PI3K/AKT/mTOR pathway is constitutively active in NSCLC $(15,16)$, not only due to PTEN inactivation but also to copy number gains of PIK3CA (12). In contrast to the low frequency of mutations, PIK3CA copy number gains have been reported in $33.1 \%$ of squamous cell lung cancer and in $6.2 \%$ of lung adenocarcinomas (11). In vitro data indicates that PI3K signalling mediates bronchioalveolar stem cell expansion initiated by oncogenic $K-R A S$, whereas oncogenic $P I K 3 C A$ mutations enhance the anchorage-independent growth and migration activity of immortalised respiratory epithelial cells (17). More importantly, the inhibition of PI3K/AKT/mTOR signalling through pharmacologic and genetic approaches induces the anti-proliferative effects on certain NSCLC cell lines, as well as in mouse models of lung cancer (12).

On the basis of this experimental evidence, it is not surprising that much effort has been devoted to the investigation of the expression profiles of various components of the PI3K/AKT/ mTOR pathway in NSCLC $(16,18-32)$, sometimes yielding inconsistent results. In particular, a comprehensive analysis of all components of this pathway, along with the PIK3CA, K-RAS, $A K T 1$ and $P T E N$ mutational status has not been performed thus far. Therefore, the aims of the present study were as follows: first, to search for any correlation between the mutational status of these 4 genes and the expression levels of the p $85 \alpha$ and p110 $\gamma$ subunits of PI3K, phosphorylated AKT (p-AKT), phosphorylated mTOR (p-mTOR), PTEN, phosphorylated p79S6K (p-p79S6K) and phosphorylated 4E-BP1 (p-4E-BP1); second, to examine the associations of these molecules with clinicopathological characteristics; and third, to assess their potential prognostic utility in a series of NSCLC patients.

\section{Materials and methods}

Cases and classification. This is a study of 102 adult Caucasian patients of Greek ethnicity with NSCLC (36) diagnosed between 2004 and 2010 at the First Department of Pathology, University of Athens Medical School, for whom archival primary tumour material at diagnosis, prior to chemo/radiotherapy, was available. The study was approved by the Ethics Committee of the University of Athens Medical School and informed consent was obtained from each patient prior to enrolment in the study. The demographic data and follow-up information of our patients are shown in Table I. The total sample set consisted of 71 surgical specimens and 31 biopsies and was composed of 14 females and 88 males with a median age of 71 years (range, 46-89). The pathological stage of each tumour was assigned following the guidelines from the 7th edition of the TNM classification (1) and was known for 71 patients: 23 patients had stage I disease and 48 had stage II-III disease. The medical records of the patients were collected to obtain information regarding patient survival status and cause of death was obtained from the medical records and/or interview with the family. Follow-up information was available for 75 patients.

\section{PIK3CA, AKT1, PTEN and K-RAS mutational analysis}

DNA extraction from paraffin-embedded tissues. Sections (10- $\mu \mathrm{m}$-thick) were cut from paraffin-embedded tissue blocks following tumour enrichment under a light microscope. DNA was extracted from the selected tissue areas following a standard DNA extraction kit protocol (NucleoSpin Tissue; Macherey-Nagel, Duren, Germany). The extracted DNA was quantified on a Picodrop Microliter spectrophotometer.

High resolution melting analysis (HRMA). PIK3CA exons 9 and 20, AKT1 exon 4,PTEN exons 7 and 8, as well as $K-R A S$ codons 12 and 13 were screened for mutations in 61 tumour specimens using HRMA on a LightCycler 480 (obtained from Roche Diagnostics, GmbH, Mannheim, Germany). Each reaction consisted of $20 \mathrm{ng}$ DNA, $200 \mathrm{nmol} / \mathrm{l}$ of each primer, $10 \mu \mathrm{l}$ LightCycler 480 HRM Master Mix (Roche) and $3.5 \mathrm{mM}$ $\mathrm{MgCl}_{2}$, in a total volume of $20 \mu \mathrm{l}$. The profile used in the Light Cycler was: $95^{\circ} \mathrm{C}$ for $10 \mathrm{~min}$, followed by 50 cycles of $95^{\circ} \mathrm{C}$ for $10 \mathrm{sec}, 58-60^{\circ} \mathrm{C}$ for $15 \mathrm{sec}$ and $72^{\circ} \mathrm{C}$ for $7 \mathrm{sec}$. DNA samples from colorectal cancers or cell lines harbouring $K-R A S$ codon 12 and 13 mutations or exon 9 and 20 PIK3CA mutations were used as the positive controls for HRM analysis. In detail, for PIK3CA exon 20 mutational analysis we examined DNA extracted from the HCT-116 colon cancer cell line (PIK3CA mutation, p.H1047R). For the other genes, previously identified mutant samples from colorectal cancers were used. The sequences of the primers for the K-RAS, PIK3CA and AKTI genes have been published previously (33). The primers used for PTEN gene analysis were as follows: PTEN exon 7 forward, 5'-TCGTTTTTGACAGTTT GACAGTT-3' and reverse, 5'-GGATATTTCTCCCAATGAAA GTAAA-3'; and PTEN exon8forward,5'-GTCATTTCATTTCTTTTTCTTTTCTTT-3' and reverse, 5'-CAACAACCCCCA CAAAT-3'. 
Table I. Clinicopathological characteristics of the 102 patients enrolled in the present study.

\begin{tabular}{lr}
\hline Characteristic & No. of patients \\
\hline Gender & \\
Female & $14(13.73)$ \\
Male & $88(86.27)$ \\
Histological type & \\
Adenocarcinoma & $39(38.24)$ \\
Squamous cell carcinoma & $48(47.06)$ \\
Adenosquamous carcinoma & $9(8.82)$ \\
Large cell carcinoma & $3(2.94)$ \\
Sarcomatoid carcinoma & $3(2.94)$ \\
Histological grade & \\
I & $3(2.94)$ \\
II & $47(46.08)$ \\
III & $52(50.98)$ \\
Stage & \\
I & $23(32.39)$ \\
II & $35(49.30)$ \\
III & $13(18.31)$
\end{tabular}

Tumour status

$\mathrm{T} 1$

$10(14.08)$

$\mathrm{T} 2$

$41(57.75)$

T3

$20(28.17)$

Nodal status

No

$50(70.42)$

19 (26.76)

$\mathrm{N} 1$

2 (2.82)

Recurrence rate

Absence

27 (49.09)

Presence

$28(50.91)$

Follow-up

Alive

68 (66.67)

Follow-up: 33

(2-108) months

Dead from disease

34 (33.34)

Follow-up: 12

(1-96 months)

Age

Median (range) tions. The results were verified by the sequencing of at least 2 independent PCR products. $K-R A S$ mutations at codon 12 were verified by RFLP analysis as described previously (34). $A K T 1$ mutations were identified using pyrosequencing with the Q24 pyrosequencer according to the manufacturer's instructions (Qiagen GmbH, Hilden, Germany).

Immunohistochemistry. Immunostaining was performed on paraffin-embedded $4-\mu \mathrm{m}$-thick sections of formalin-fixed tumour tissue using the two-step peroxidase conjugated polymer technique (Dako Envision kit; Dako, Carpinteria, CA, USA). The primary antibodies used are listed in Table II. In the negative controls primary antibodies were substituted with non-immune serum.

Two pathologists (Eleni Trigka and Penelope Korkolopoulou) viewed the first 20 cases for each antibody together to obtain the consensus regarding the evaluation, without knowledge of the clinical data. The remaining cases were then examined by a pathologist (Eleni Trigka) and another 20 cases were examined for reproducibility by a second pathologist (Penelope Korkolopoulou). Nuclear and cytoplasmic immunoreactivity was recorded separately. For statistical analysis only the predominant pattern i.e., cytoplasmic for p-mTOR and PTEN and nuclear for p-p70S6K, p85 $\alpha \mathrm{PI} 3 \mathrm{~K}$ and p-4E-BP1 was taken into account. For p-AKT and p1 $10 \gamma \mathrm{PI} 3 \mathrm{~K}$ both nuclear and cytoplasmic expression patterns were analysed separately. A Histo-score (H-score) based on the percentage of stained neoplastic cells multiplied by the staining intensity was calculated, as previously described (35).

Statistical analysis. Statistical analysis was performed by a biostatistician (Georgia Levidou). In the basic statistical analysis, p-mTOR, p-p70S6K, PTEN, p-AKT, p4E-BP1, p110 $\gamma$ PI3K and $\mathrm{p} 85 \alpha \mathrm{PI} 3 \mathrm{~K} \mathrm{H}$-scores were treated as continuous variables. Correlations among the immunohistochemical expression of the investigated proteins as well as with the clinicopathological parameters were examined using non-parametric tests with correction for multiple comparisons where necessary (KruskalWallis ANOVA, Mann-Whitney U test, Spearman's rank correlation co-efficient, Fisher's exact test and $\chi^{2}$ as appropriate).

Survival analysis was performed using death by disease as the endpoint for cancer-specific survival (CSS). The effect of various parameters on clinical outcome was assessed by comparing the groups using the log-rank test. Multivariate analysis was performed using Cox's model. For statistical calculations the statistical package STATA 11.0 for Windows was used. All results with a two-sided p-value $\leq 0.05$ were considered to indicate statistically significant differences.

\section{Results}

PIK3CA, AKTI, PTEN and K-RAS mutations (Fig. 1). Overall, 61 cases were analysed for the presence of PIK3CA, AKT1, $P T E N$ and $K-R A S$ mutations. Molecular analysis was successful as regards the presence of activating mutations at exons 9 and 20 of the PIK3CA gene in 60 and 59 cases, respectively, whereas mutations at codons 12 and 13 of the $K$-RAS gene were observed in 54 cases, at exon 4 of $A K T 1$ gene in 57 cases and at exons 7 and 8 of PTEN gene in 50 and 49 cases, respectively, by

high resolution melting analysis. PI3KCA and PTEN mutations
Sequencing, pyrosequencing and restriction fragment length polymorphism (RFLP) analysis. PIK3CA (exons 9 and 20) and PTEN (exons 7 and 8) PCR products shown to be positive by HRM, were sequenced using the BigDye Terminator Cycle Sequencing kit (Applied Biosystems, Foster City, CA, USA) The sequencing products were analysed on an ABI PRISM 310 Genetic Analyzer (Applied Biosystems). PCR primers were also used for sequencing analysis to confirm the presence of muta- 


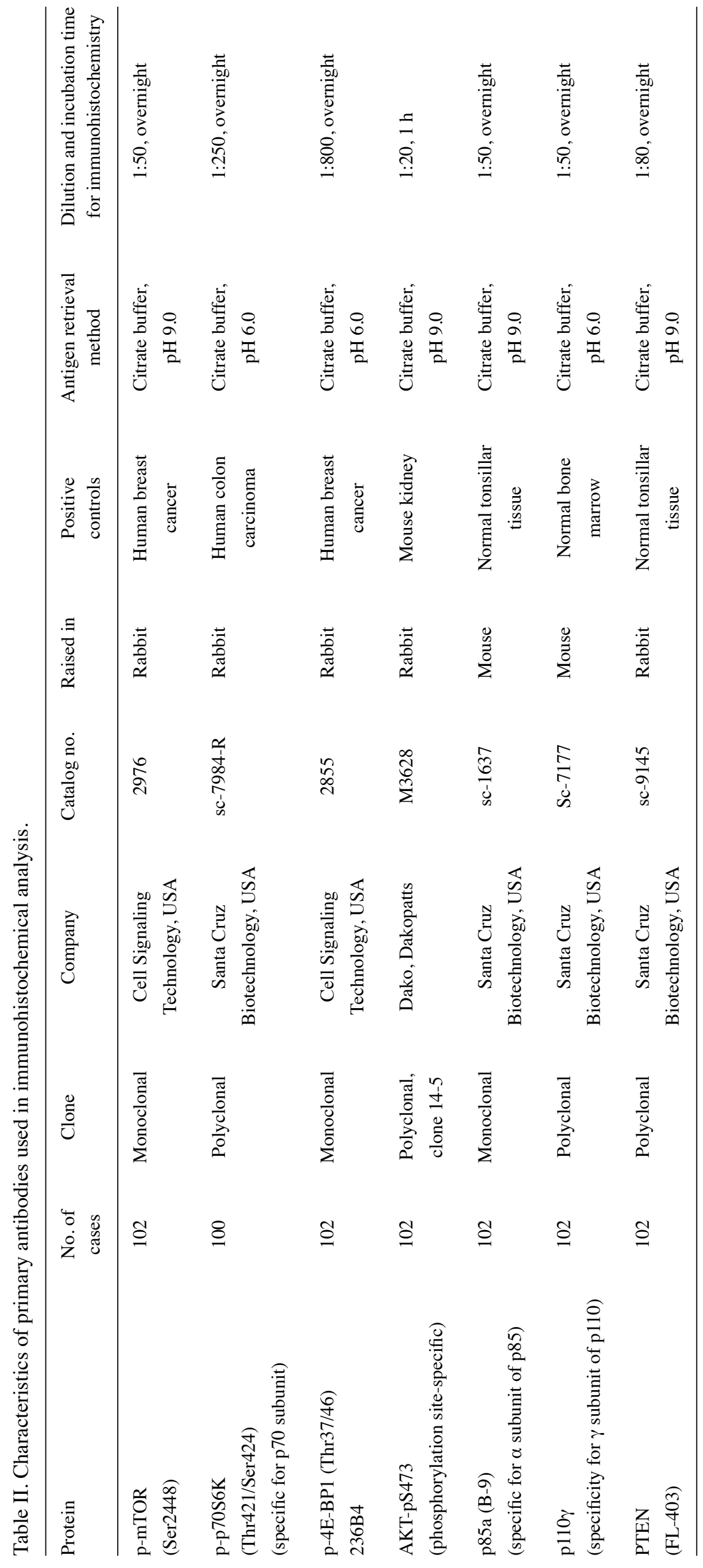



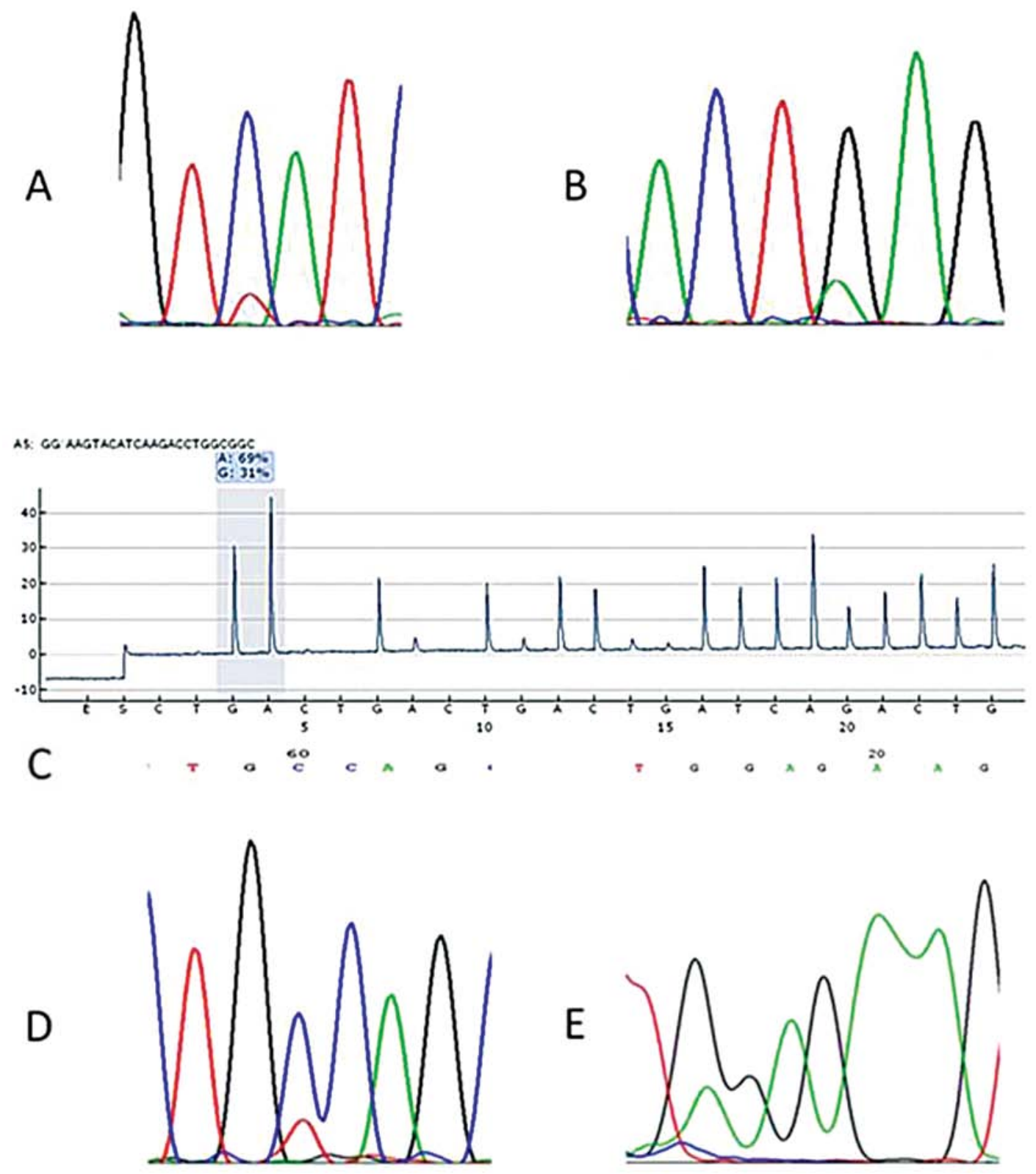

Figure 1. (A) Sequencing analysis of the PIK3CA gene, exon 20 showing a $\mathrm{C}>\mathrm{T}$ substitution (reverse sequencing) at nucleotide 3052 , leading to a mutation at codon 1018 (p.D1018N, c.3052G>A). (B) Sequencing analysis of the PIK3CA gene, exon 9. A transition G>A at nucleotide 1633 (c.1633G>A) is observed, leading to a mutation at codon 545 (p.E545K). (C) Pyrosequencing results for the $A K T 1$ gene exon 4 displaying a substitution G>A at nucleotide 49, leading to mutation at codon 17 (p.E17K). (D) Sequencing analysis of the PTEN gene, exon 7. A C >T transition at nucleotide 654 (c.654 C>T) was observed, leading to a mutation at codon 218 (p.C218C). (E) Sequencing analysis of the PTEN gene, exon 8 showing a G>A substitution (reverse sequencing) at nucleotide 1016, leading to a mutation at codon 339 (p.P339L, c.1016C $>$ T).

were identified by sequencing analysis, $A K T 1$ by pyrosequencing, whereas $K-R A S$ mutations at codon 12 were verified by RFLP analysis. PIK3CA mutations were observed in $5 \%$ of the examined samples (3/59). In particular, 1 sample displayed a $\mathrm{G}>\mathrm{A}$ transition at nucleotide 3052 (c.3052G $>$ A) leading to an aspartic acid to asparagine substitution (p.D1018N), which is rare and has been previously identified in thyroid cancer [Sanger Institute Catalogue Of Somatic Mutations In Cancer (COSMIC) database] (Fig. 1A). In addition, 2 samples displayed a common PIK3CA mutation at exon 9, identified as a $\mathrm{G}>\mathrm{A}$ transition at nucleotide 1633 (c.1633G>A) leading to a glutamic acid to lysine substitution (p.E545K) (Fig. 1B). Two PIK3CA mutations (in exons 9 and 20) were observed in squamous cell lung carcinomas and 1 in an adenocarcinoma. As regards $A K T 1$ mutations, the most frequent alteration, namely a $\mathrm{G}>\mathrm{A}$ transition at nucleotide 49 (c.49G>A), causing glutamic acid to lysine substitution at hotspot codon 17 (p.E17K) was found in 1 adenocarcinoma case (1/57 of the examined cases, $1.75 \%$ ) (Fig. 1C). Furthermore, 10 out of the 54 examined cases (18.5\%) were positive for $K$-RAS mutations at codon 12. PTEN 


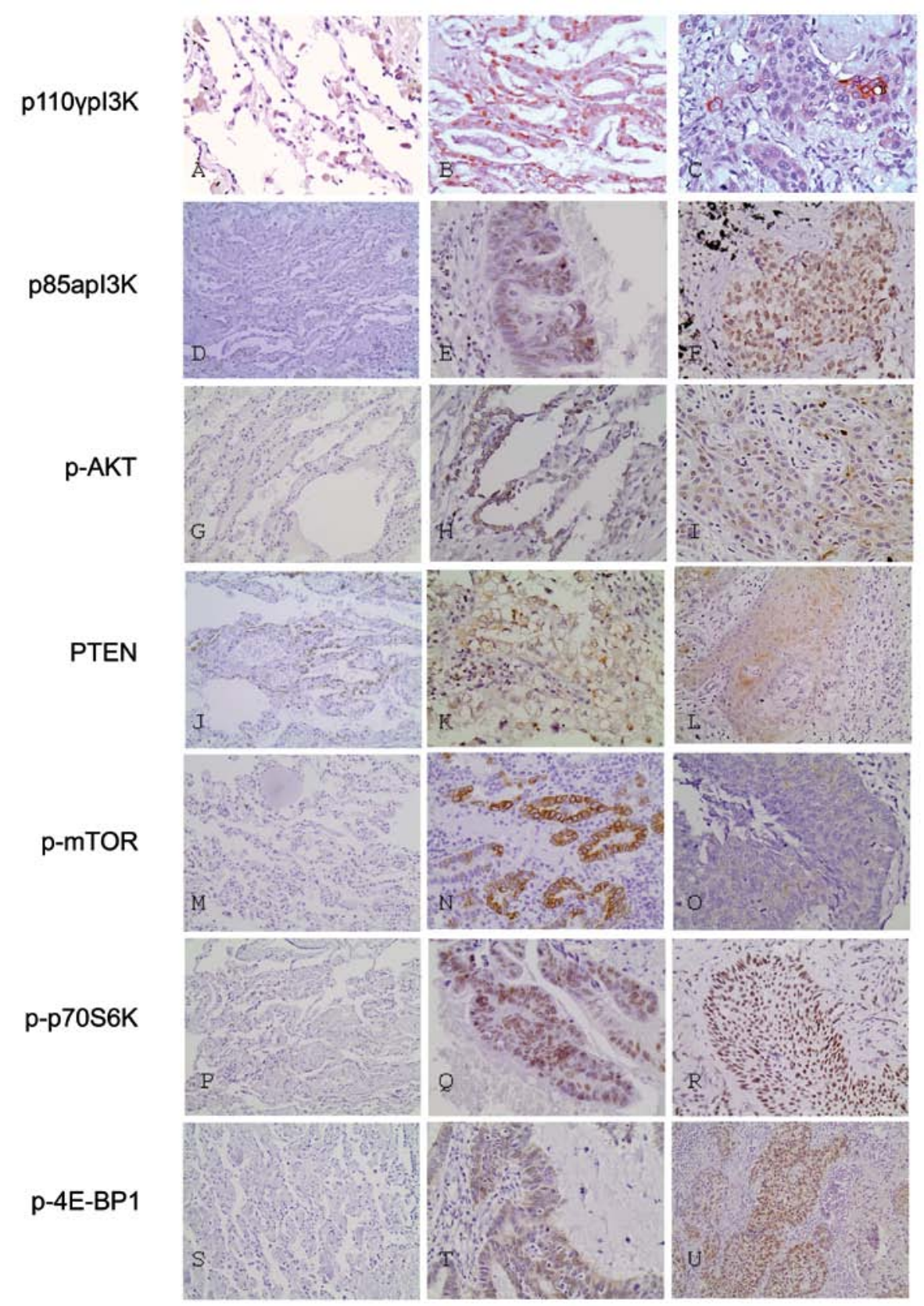

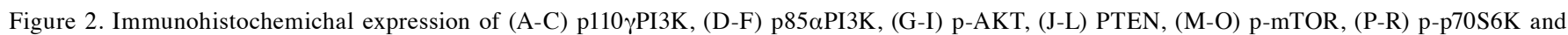
(S-U) p-4E-BP1 in (A, D, G, J, M, P and S) normal lung tissue, (B, E, H, K, N, Q and T) adenocarcinomas and (C, F, I, L, O, R and U) squamous cell carcinomas.

mutations were also encountered in 5 cases, 1 in exon $7(1 / 50$, $2 \%)$ and 4 in exon $8(4 / 49,8.2 \%)$. In detail, a PTEN exon $7 \mathrm{C}>\mathrm{T}$ transition (c.654 C>T) leading to a silent mutation (p.C218C) was found in 1 squamous carcinoma (Fig. 1D). Accordingly, as far as PTEN exon 8 is concerned, a $\mathrm{C}>\mathrm{T}$ transition (c.1016C $>\mathrm{T}$ ) leading to a proline to leucine substitution at codon 339 (p.P339L) was found in 1 adenocarcinoma case (Fig. 1E). Furthermore, a $\mathrm{G}>\mathrm{A}$ substitution $(\mathrm{c} .881 \mathrm{G}>\mathrm{A})$ at codon 881 leading to p.S294N mutation and a $\mathrm{C}>\mathrm{T}(\mathrm{c} .883 \mathrm{C}>\mathrm{T})$ silent mutation (p.L295L) were found in 2 squamous cell carcinoma cases. Finally, an adenosquamous carcinoma case showed a $\mathrm{C}>\mathrm{T}$ silent mutation at codon 850 (c.850C $>$ T), p.T286T). Notably, 4 out of 5 PTEN mutations observed were $\mathrm{C}>\mathrm{T}$ substitutions. In our cohort, PIK3CA mutations were not found to co-exist with
$K$-RAS, AKT1 or PTEN mutations. The single AKT1 mutant case displayed one of the highest nuclear p110 $\gamma \mathrm{PI} 3 \mathrm{~K}$ H-scores (i.e., 20). Moreover, all cases with a PTEN mutation displayed p110 $\gamma \mathrm{PI} 3 \mathrm{~K}$ cytoplasmic immunoreactivity $(\mathrm{p}=0.0506)$. Finally, the presence of PTEN mutations correlated with the presence of nodal metastasis (Fisher's exact test, $\mathrm{p}=0.047$ ).

PI3K/AKT/mTOR pathway in NSCLCs (Fig. 2). p-mTOR immunoreactivity was cytoplasmic and/or membranous in $58 / 102$ cases $(56.86 \%)$ and nuclear in $7 / 102$ cases $(6.8 \%)$. Nuclear p-p70S6K and p-4E-BP1 immunoexpression was observed in $96 / 100$ cases $(96 \%)$ and $71 / 102$ cases $(69.61 \%)$. Tumourinfiltrating lymphocytes and endothelial cells expressed both proteins and served as the internal positive controls in each 
A

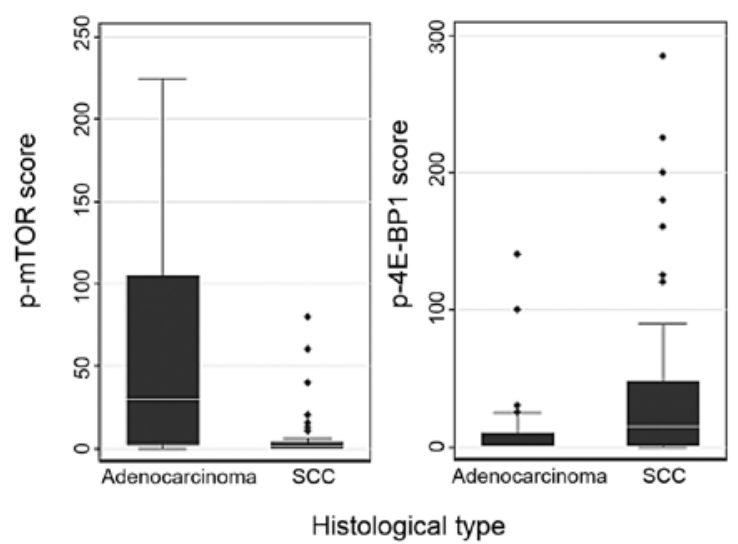

C

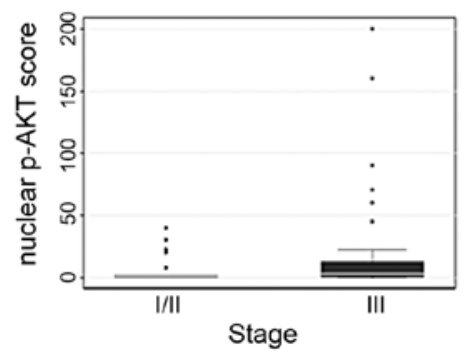

B
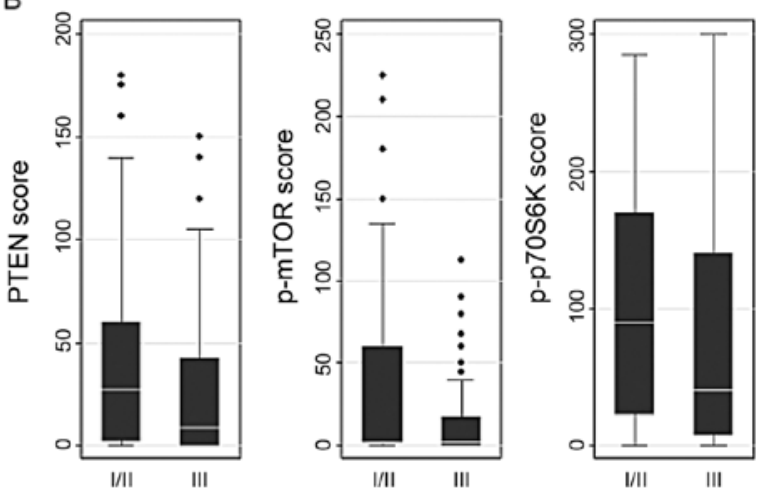

Histological grade

D
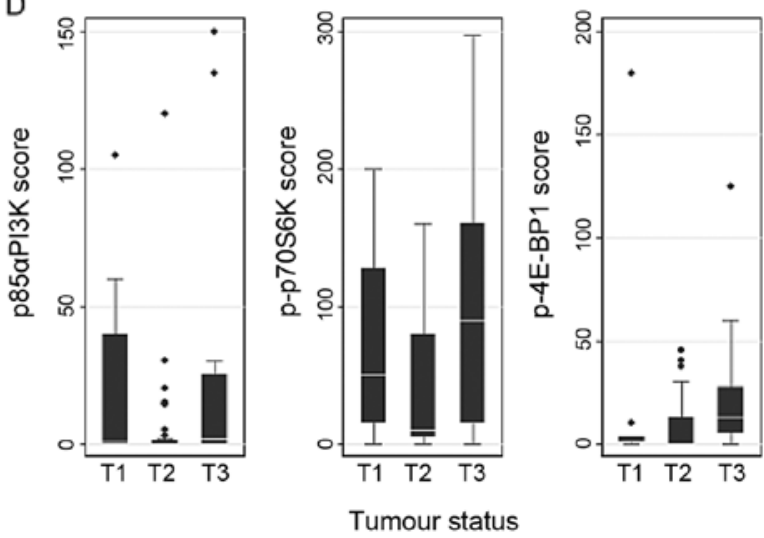

Figure 3. Box-plots representing the association of (A) p-mTOR and p-4E-BP1 H-score with histological diagnosis; (B) PTEN, p-mTOR and p-p70S6K H-score with histological grade; and (C) nuclear p-AKT H-score with stage and (D) p85 $\alpha \mathrm{PI} 3 \mathrm{~K}$, p-p70S6K and p-4E-BP1 H-score with tumour status. SCC, squamous cell carcinoma.

case. Sixty-eight cases $(68 / 100,68 \%)$ co-expressed p-p70S6K and p-mTOR, with $28 \mathrm{p}$-p70S6K positive cases being negative for p-mTOR $(28 / 96,21.16 \%)$. All these cases but one, however, displayed cytoplasmic p-AKT $(27 / 28,96.42 \%)$. Fifty-three cases co-expressed p-mTOR and p-4E-BP1 (53/102,51.96\%), whereas 18 cases positive for $\mathrm{p}-4 \mathrm{E}-\mathrm{BP} 1$ were negative for $\mathrm{p}-\mathrm{mTOR}(18 / 71$, $25.35 \%)$. The percentage of co-expression of all 3 components of the mTOR cascade rose to $51 \%$ (51/100 cases). Two cases (2/100, $2 \%$ ) were triple-negative for the p-mTOR pathway components, whereas all the cases that were positive for $\mathrm{p}$-mTOR but double negative for p-p70S6K and p-4E-BP1 expressed p-AKT.

p-AKT immunoreactivity was mainly cytoplasmic $(95 / 102$, $93.14 \%)$ with 85 cases $(85 / 102,83.33 \%)$ showing nuclear immunoexpression. Cytoplasmic p-AKT was co-expressed with all 3 mTOR pathway components in 49/100 cases (49\%) and nuclear in 45/100 (45\%) cases. p85 $\alpha \mathrm{PI} 3 \mathrm{~K}$ nuclear expression was recorded in 58/102 cases (56.86\%). p85 $\alpha \mathrm{PI} 3 \mathrm{~K}$ was co-expressed with cytoplasmic p-AKT in 56/102 (54.9\%) cases and with nuclear p-AKT in 48/102 (47.05\%) cases. p85aPI3K-positive cases displayed higher levels of p-AKT cytoplasmic immunoreactivity (Mann-Whitney U test, $\mathrm{p}=0.0442$ ). The co-expression of p $85 \alpha \mathrm{PI} 3 \mathrm{~K}$ with cytoplasmic p-AKT and all 3 members of the mTOR pathway was observed in 33 cases $(33 / 100,33 \%)$. p110 $\gamma \mathrm{PI} 3 \mathrm{~K}$ cytoplasmic immunoreactivity was observed in 42/102 (41.185) cases, whereas only $19.61 \%$ (20/102) of cases displayed nuclear immunoexpression. All p110 $\gamma \mathrm{PI} 3 \mathrm{~K}$-positive cases displayed p-AKT cytoplasmic immunoexpression (Fisher's exact test, $\mathrm{p}=0.039)$. The co-expression of cytoplasmic or nuclear p110 $\gamma \mathrm{PI} 3 \mathrm{~K}$ with cytoplasmic p-AKT and all 3 members of the mTOR pathway was observed in $22(22 / 100,22 \%)$ and 15 $(15 / 100,15 \%)$ cases, respectively. PTEN cytoplasmic immunoreactivity was observed in 79/102 cases $(77.45 \%)$ with 6 cases showing nuclear immunoreactivity $(6 / 102,5.8 \%)$. Twenty-one of the cases that displayed cytoplasmic p-AKT immunoreactivity (21/95, 22.1\%) were negative for PTEN.

The correlations among these proteins are shown in Table III. A significant positive correlation was established between cytoplasmic p-AKT and p-mTOR, p-p70S6K or p-4E-BP1, between p85 $\alpha \mathrm{PI} 3 \mathrm{~K}$ and p-mTOR, p-p70S6K or p-4E-BP1 as well as between p-mTOR and p-p70S6K, p-p70S6K and p-4E-BP1. p110 $\gamma \mathrm{PI} 3 \mathrm{~K}$ nuclear and cytoplasmic immunoreactivity both positively correlated with p-mTOR, p-p70S6K or p-4E-BP1, whereas a positive correlation was observed between nuclear p110 $\gamma \mathrm{PI} 3 \mathrm{~K}$ and $\mathrm{p} 85 \alpha \mathrm{PI} 3 \mathrm{~K}$ immunoexpression.

p-mTOR, p-p70S6K, p85aPI3K and p-AKT were negative in the alveolar epithelium but weakly positive in seromucous glands and normal bronchi. p110 $\gamma \mathrm{PI} 3 \mathrm{~K}$ was also negative in the alveolar epithelium, whereas a nuclear immunoreactivity was observed in the normal bronchial epithelium. PTEN was present in the alveolar and normal bronchial epithelium, as well as in seromucous glands. p-4E-BP1 was absent in the normal lung epithelium.

Association between PI3K/AKT/mTOR pathway components and clinicopathological features (Table IV and Fig. 3). p-mTOR immunoreactivity prevailed in adenocarcinomas 


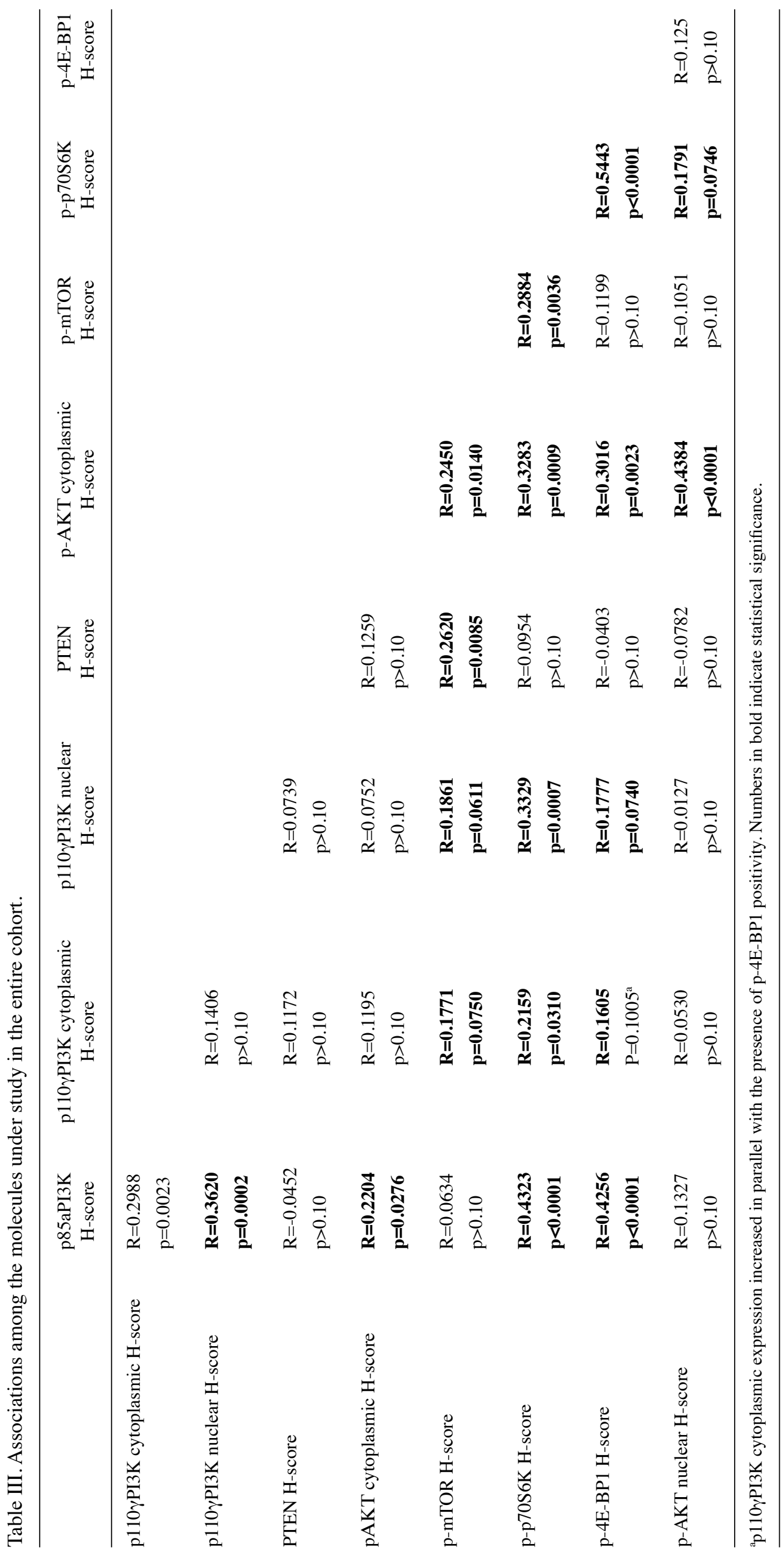




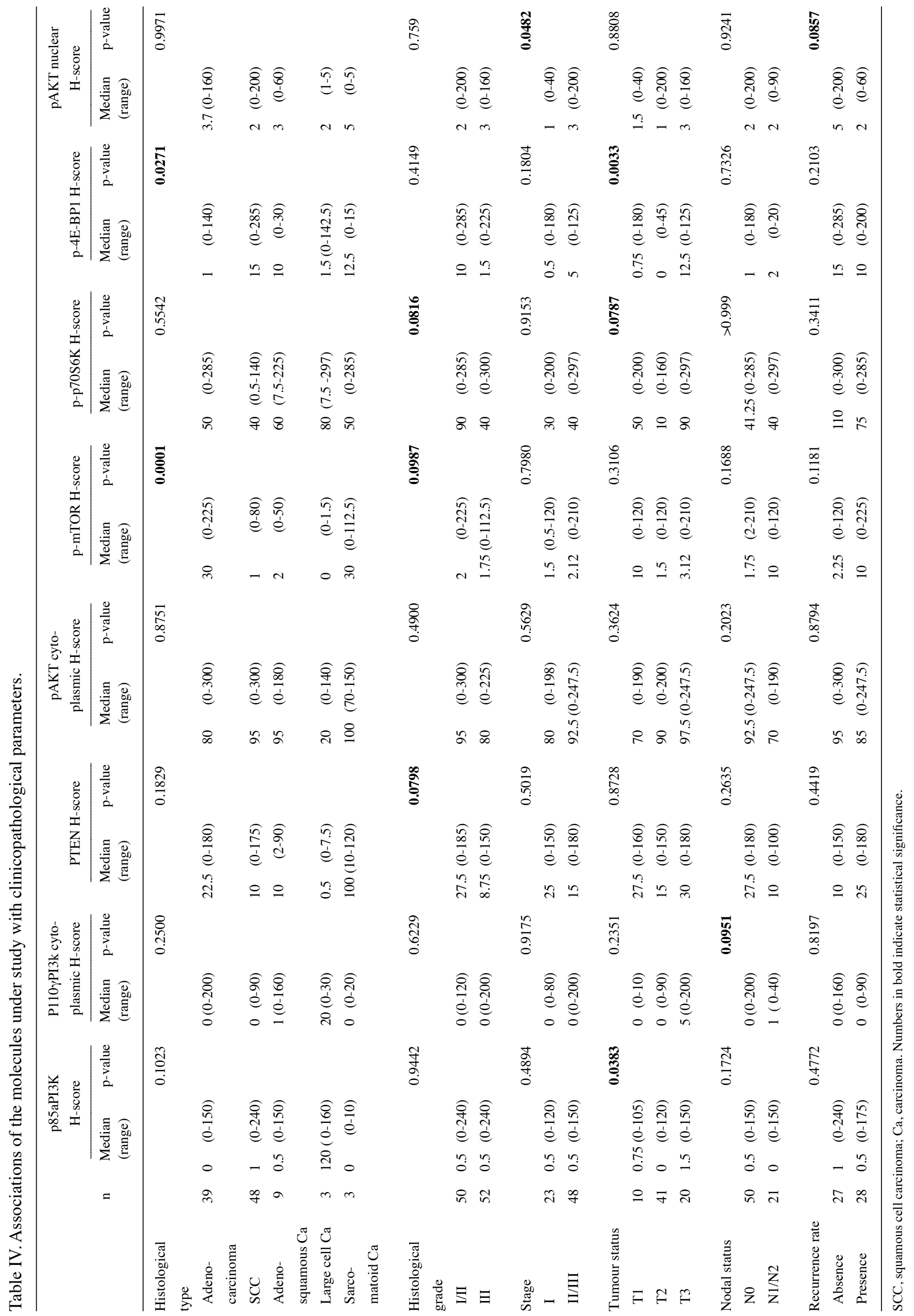


Table V. Results of univariate survival analysis for cancer-specific survival (log-rank test).

\begin{tabular}{|c|c|c|c|}
\hline Variable & $\begin{array}{l}\text { Entire } \\
\text { cohort } \\
\text { p-value }\end{array}$ & $\begin{array}{l}\text { Adeno- } \\
\text { carcinoma } \\
\text { p-value }\end{array}$ & $\begin{array}{c}\text { SCC } \\
\text { p-value }\end{array}$ \\
\hline Age & 0.9243 & 0.1468 & 0.8511 \\
\hline \multicolumn{4}{|l|}{ Gender } \\
\hline (Fenale vs. male) & 0.7871 & 0.5917 & 0.4468 \\
\hline Histological type & 0.4559 & - & - \\
\hline Histological grade & 0.8496 & 0.4102 & 0.8404 \\
\hline \multicolumn{4}{|l|}{ Stage } \\
\hline (I vs. II/III) & 0.4824 & 0.6171 & 0.2716 \\
\hline \multicolumn{4}{|l|}{ Tumour status } \\
\hline (T1 vs. T2 vs. T3) & 0.8289 & 0.5127 & 0.9425 \\
\hline \multicolumn{4}{|l|}{ Nodal status } \\
\hline (N0 vs. N1/N2) & 0.4559 & 0.4142 & 0.4059 \\
\hline \multicolumn{4}{|l|}{ PTEN mutations } \\
\hline (absence vs. presence) & 0.4669 & 0.5892 & 0.1284 \\
\hline \multicolumn{4}{|l|}{$K-R A S$ mutations } \\
\hline (absence vs. presence) & 0.5892 & 0.5596 & 0.7389 \\
\hline \multicolumn{4}{|l|}{ PIK3CA mutations } \\
\hline (absence vs. presence) & 0.7434 & 0.7228 & 0.8348 \\
\hline $\begin{array}{l}\text { AKT1 mutations } \\
\text { (absence vs. presence) }\end{array}$ & 0.6305 & 0.6821 & a \\
\hline $\begin{array}{l}\text { p85aPI3K H-score } \\
\text { (negative vs. positive) }\end{array}$ & 0.6983 & 0.2360 & 0.4510 \\
\hline $\begin{array}{l}\text { p110 } \gamma \text { PI3K cytoplasmic } \\
\text { (negative vs. positive) }\end{array}$ & 0.2964 & 0.2964 & 0.4113 \\
\hline $\begin{array}{l}\text { p110 } 1 \text { PI3K nuclear H-sc } \\
\text { (negative vs. positive) }\end{array}$ & 0.9352 & 0.9540 & 0.5390 \\
\hline $\begin{array}{l}\text { PTEN H-score } \\
(<10 \text { vs. } \geq 10)\end{array}$ & 0.8559 & 0.7343 & 0.7916 \\
\hline $\begin{array}{l}\text { p-AKT cytoplasmic H-s } \\
(<90 \text { vs. } \geq 90)\end{array}$ & 0.7398 & 0.0657 & 0.3678 \\
\hline $\begin{array}{l}\text { p-AKT nuclear H-score } \\
(<2.125 \text { vs. } \geq 2.125)\end{array}$ & 0.2781 & 0.5245 & 0.2774 \\
\hline $\begin{array}{l}\text { p-mTOR H-score } \\
(<2 \text { vs. } \geq 2)\end{array}$ & 0.2752 & 0.7156 & 0.2890 \\
\hline $\begin{array}{l}\text { p-p70S6K H-score } \\
(<77.5 \text { vs. } \geq 77.5)\end{array}$ & 0.7273 & 0.1715 & 0.4448 \\
\hline $\begin{array}{l}\text { p-4E-BP1 H-score } \\
\text { (negative vs. positive) }\end{array}$ & 0.3202 & 0.0306 & 0.7362 \\
\hline $\begin{array}{l}\mathrm{SCC} \text {, squamous cell car } \\
\text { is not any } A K T 1 \text { mutatio } \\
\text { statistical significance. }\end{array}$ & $\begin{array}{l}\text { Tannot be } \\
\text { ubgroup. }\end{array}$ & $\begin{array}{l}\text { lculated be } \\
\text { mbers in } b\end{array}$ & $\begin{array}{l}\text { use there } \\
\text { indicate }\end{array}$ \\
\hline
\end{tabular}

Table VI. Cox proportional hazards estimation model for the entire cohort.

\begin{tabular}{|c|c|c|c|c|}
\hline \multirow[b]{2}{*}{$\begin{array}{l}\text { Concurrent overexpression } \\
\text { of p-AKT-p-4E-BP1 }\end{array}$} & \multirow{2}{*}{$\begin{array}{c}\begin{array}{c}\text { Hazard } \\
\text { ratio }(\mathrm{HR})\end{array} \\
13.419\end{array}$} & \multirow{2}{*}{$\begin{array}{c}\text { p-value } \\
0.036\end{array}$} & \multicolumn{2}{|c|}{$\begin{array}{l}95 \% \text { confidence } \\
\text { interval of } \mathrm{HR}\end{array}$} \\
\hline & & & 1.184 & 152.121 \\
\hline $\begin{array}{l}\text { Histological type } \\
\text { (adenocarcinoma }\end{array}$ & 5.160 & 0.133 & 0.608 & 43.810 \\
\hline vs. other type) & & & & \\
\hline Interaction term ${ }^{\mathrm{a}}$ & 0.035 & 0.024 & 0.002 & 0.641 \\
\hline Histological grade & 1.052 & 0.932 & 0.333 & 3.322 \\
\hline Stage & 1.009 & 0.992 & 1.156 & 6.526 \\
\hline
\end{tabular}

(Kruskal Wallis, ANOVA, $\mathrm{p}=0.0001$ ), whereas p-4E-BP1 $\mathrm{H}$-score was lower in this histological subtype (Kruskal Wallis, ANOVA, $p=0.0271$ ) when compared to the remaining tumour types. In particular, p-mTOR expression was significantly higher in adenocarcinomas when compared to squamous cell carcinomas (Mann-Whitney U test, Bonferoni correction, $\mathrm{p}=0.0416$ ), whereas p-4E-BP1 was significantly higher in squamous cell carcinomas when compared to adenocarcinomas (MannWhitney U test, Bonferoni correction, $\mathrm{p}=0.0032$ ). Moreover, p110 $\gamma \mathrm{PI} 3 \mathrm{~K}$ nuclear positivity was more frequently encountered in adenocarcinomas $(12 / 39,30.77 \%)$ compared to the remaining tumour histological types $(8 / 63,12.7 \%),\left(\chi^{2}\right.$ test, $\left.p=0.025\right)$.

Furthermore a positive correlation was observed between p-4E-BP1 or p-AKT nuclear immunoexpression and tumour status (Kruskal Wallis, ANOVA, T1 vs. T2 vs. T3, $\mathrm{p}=0.0033$ ) or stage (Mann-Whitney $\mathrm{U}$ test, $\mathrm{p}=0.0482$ ), respectively, whereas the respective correlation between p-p70S6K immunoreactivity and tumour status was an inverse correlation and of marginal significance (Kruskal Wallis, ANOVA, T1 vs. T2 vs. T3, $\mathrm{p}=0.0787$ ). The former correlation remained in adenocarcinomas. p $85 \alpha \mathrm{PI} 3 \mathrm{~K}$ also correlated with tumour status, with the T2 tumours exhibiting higher levels of expression (Kruskal Wallis, ANOVA, T1 vs. T2 vs. T3, p=0.0383) and marginally correlated with nodal status in squamous cell carcinomas ( $\mathrm{p}=0.0887)$. p110 $\gamma \mathrm{PI} 3 \mathrm{~K}$ immunoreactivity also positively correlated with the presence of nodal metastasis (Mann-Whitney $\mathrm{U}$ test, $\mathrm{p}=0.0951$ ).

Inverse correlations, although of borderline significance were also obtained between histological grade and PTEN, p-mTOR and p-p70S6K immunoreactivity (Mann Whitney U test, I/II vs. III, $\mathrm{p}=0.0798, \mathrm{p}=0.0987$ and 0.0816 , respectively), the latter being significant in squamous cell carcinomas $(\mathrm{p}=0.0298)$.

Survival analysis. Univariate survival analysis was performed for the entire cohort and separately for adenocarcinomas and squamous cell carcinomas. The results are shown in Table V. 
A

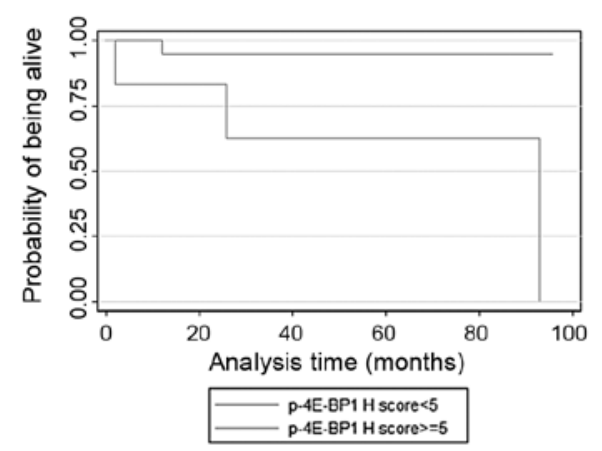

B

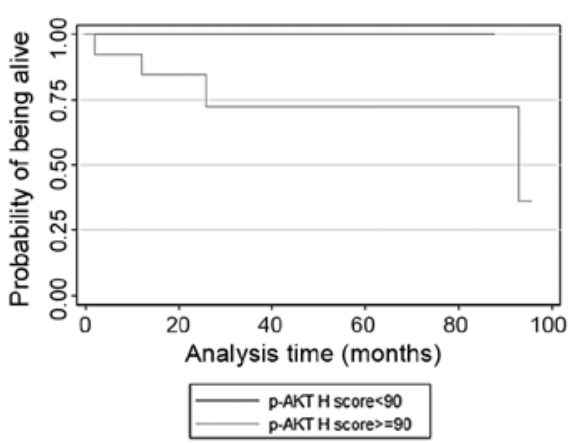

C

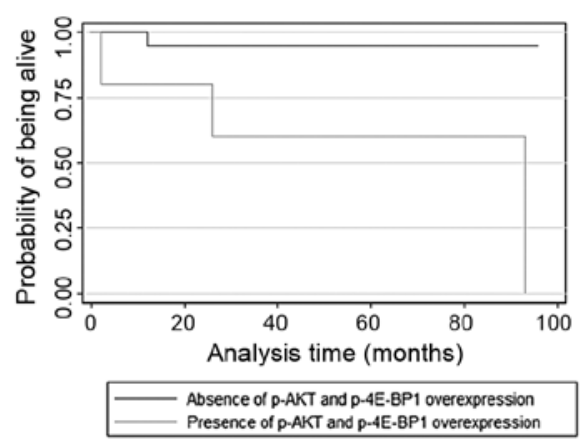

Figure 4. Kaplan-Meier curves for cancer-specific survival according to (A) p-4E-BP1, (B) cytoplasmic p-AKT and (C) combined p-4E-BP1/cytoplasmic p-AKT immunoexpression.

The only parameter that adversely affected survival in adenocarcinomas was $\mathrm{p}-4 \mathrm{E}-\mathrm{BP} 1$ immunoreactivity $(\mathrm{p}=0.0306$, Fig. 4A), with cytoplasmic p-AKT expression attaining a marginal significance in this regard ( $p=0.0657$, Fig. 4B). In addition, we evaluated the prognostic effect of the combination of these 2 differentially activated proteins using Kaplan-Meier analysis. Subjects with adenocarcinomas showing p-AKT and p-4E-BP1 overexpression had significantly worse prognosis than the other 2 combinations ( $\mathrm{p}=0.0252$, Fig. $4 \mathrm{C}$ ).

Multivariate survival analysis was performed for the entire cohort. In order to improve the stability and power, we adjusted a multivariate model including the combination of $\mathrm{p}$-AKT and p-4E-BP1 overexpression along with histological grade and stage and an interaction term between concurrent p-AKT and p-4E-BP1 overexpression and histological type. This model is presented in Table VI. In particular, the combination of $\mathrm{p}$-AKT and p-4E-BP1 overexpression was proven to be an independent predictor of adverse prognosis, with the interaction term being significant, validating the assumption of a significant interaction between the effect of these molecules on survival and histological type.

\section{Discussion}

The PI3K/AKT/mTOR pathway has attracted broad scientific and clinical interest in NSCLC, not only due to the fact that its aberrant activation promotes resistance to chemo/radiotherapy in vitro (15), but also since its components can be targeted for therapeutic purposes. Given the relatively common occurrence of PTEN and EGFR gene alterations, NSCLC has logically been considered a suitable candidate for the therapeutic use of molecules (e.g., rapamycin) inhibiting the PI3K/AKT/mTOR cascade (36). However, the results of previous clinical trials have tempered initial optimism showing that mTOR inhibitors have a limited efficacy as single agents in NSCLC (37). The insufficiency of therapeutic response may be somewhat related to the non-specific selection of patients for m-TOR inhibition (21). It is, therefore, hypothesised that delineating protein expression profiles of a wide array of molecules participating in PI3K/ AKT/mTOR signalling may aid in the more accurate selection of NSCLC patients with a greater likelihood to respond to the inhibition of this pathway. Another reason accounting for the modest antitumour activities of rapamycin is the abrogation of the feedback inhibition of EGFR signalling and the promotion of AKT activation (22).

The incidence of PIK3CA mutations recorded in the present series is in accordance with that recorded in the literature, which ranges between 1.6 (11) and 5\% (38). A total of 2 out of 3 mutations were observed in the squamous cell carcinoma group and were mutually exclusive with $A K T 1$ mutations in agreement with the majority of published studies (12). However, in our subset, combined K-RAS, PIK3CA, AKTI or PTEN mutations were not observed.

In our cohort, using immunohistochemistry with phosphorylation-specific antibodies, half (51\%) of the NSCLC cases were triple-positive for mTOR cascade components and essentially all (49\%) co-expressed cytoplasmic p-AKT, underlining that the activation of this pathway is common in this tumour. Of note, the percentage of cases expressing p-p70S6K $(96 \%)$ far exceeded that of p-mTOR expression (56.86\%), fitting well with the proposed direct phosphorylation of p70S6K independent of mTOR, by mitogen-activated protein kinases (MAPKs) through P90RSK, PDK1 or directly by AKT through TSC2 $(39,40)$. The latter is verified by our finding that all but one p-mTOR-negative/p-p70S6K-positive cases displayed cytoplasmic p-AKT immunoreactivity. Significant positive correlations were established between $\mathrm{p}$-mTOR and its upstream cytoplasmic p-AKT or its downstream p-p70S6K, consistent with $\mathrm{p}$-mTOR mediating the downstream effects of p-AKT on protein synthesis and proliferation in NSCLC (41). The correlation between p-AKT and p-mTOR in NSCLC has also been reported in other studies $(16,21)$ but has been questioned by Yoshizawa et al (18). Dobashiet al (22) observed little overlap in the localization of the 2 molecules, except for adenocarcinomas harbouring EGFR gene mutation, resulting in markedly increased levels of p-AKT and p-mTOR. Analogous correlations between $\mathrm{p}-\mathrm{mTOR}$ and $\mathrm{pS} 6$ or eIF4E, the partner of 4E-BP1, have been documented by Yoshizawa et al (18). Of note, we failed to elicit a correlation between $\mathrm{p}-\mathrm{mTOR}$ and $\mathrm{p}-4 \mathrm{E}-\mathrm{BP} 1$, reinforcing the assumption that an unknown pathway may be responsible for eIF4E/4e-BP1 phosphorylation, independent of p-mTOR (18). We also documented a positive association between $\mathrm{p} 85 \alpha \mathrm{PI} 3 \mathrm{~K}$ or $\mathrm{p} 110 \gamma \mathrm{PI} 3 \mathrm{~K}$ with cytoplasmic p-AKT which also applies to AKT downstream effectors. It should be noted that the above correlations remained significant in the subgroups of adenocarcinomas and squamous cell 
carcinomas, apart from the ones between cytoplasmic p-AKT and p-mTOR in adenocarcinomas. In their study on colorectal cancer, Johnson et al (42) revealed a strong correlation between p $85 \alpha \mathrm{PI} 3 \mathrm{~K}$ and p-AKT (particularly p-AKT2) in agreement with our findings. The positive correlation between p85 $\alpha$ PI3K and $\mathrm{p} 110 \gamma \mathrm{PI} 3 \mathrm{~K}$ nuclear $\mathrm{H}$-scores attests to the functional liaison between the 2 subunits of PI3K. Zito et al (27) also observed the co-expression of the 2 subunits on their NSCLC specimens.

Surprisingly, we did not observe the negative correlation between PTEN and p-AKT, neither by immunohistochemistry nor by molecular analysis, as reported by Tang et al (20) in NSCLC. Our data are corroborated by Lim et al (30) in NSCLC, as well as by studies on breast (43), renal cell (44) and urothelial bladder (45) carcinomas. In this context, it has been hypothesised that in cancer, PTEN loss activates the Rho family proteins, leading to increased cell migration and invasion through pathways independent of AKT $(43,46)$. In the present study, PTEN expression also failed to correlate with any other molecule of the PI3K/AKT/mTOR cascade consistent with the fact that mTOR and its downstream proteins, $\mathrm{p}-4 \mathrm{E}$ BP1 and p70S6K, can also be activated by other pathways, not regulated by PTEN, such as the Raf/MAPK signaling pathway (47). However, all the PTEN mutant cases displayed cytoplasmic p-AKT immunoexpression, consistent with the abrogation of PTEN inhibitory function on PI3K ability to phosphorylate AKT (14).

As regards the expression of the phosphorylated molecules and $\mathrm{p} 85 \alpha \mathrm{PI} 3 \mathrm{~K}$ in normal lung tissue, the alveolar epithelium displayed no immunoreactivity, whereas the seromucous glands and bronchial epithelium stained weakly for p-mTOR, p $85 \alpha$ PI3K, p-p70S6K and p-AKT (nuclear). These findings postulate the essential role of the above proteins in the neoplastic transformation of lung epithelial cells (21). PTEN was present in the normal bronchi and alveolar epithelium, as well as in seromucous glands. Notably, p-4E-BP1 was not observed in normal lung tissue.

An interesting finding is that $\mathrm{p}$-mTOR expression was considerably higher in adenocarcinomas, lending support to the results of Liu et al (21) and Dobashi et al (22) and disputing those of Yoshizawa et al (18), reporting higher p-mTOR levels in squamous cell carcinoma. It should be noted though, that the preferential enhancement of mTOR activation was not observed in adenocarcinoma cultured cells, suggesting the potential implication of mTOR in the morphogenesis of adenocarcinoma (22). The same applied to p110 $\gamma$ nuclear expression, in accordance with the recently reported prevalence of PI3K subunit expression in adenocarcinoma (27). From a clinical perspective, these findings raise the issue of the selective response of patients with adenocarcinoma to mTOR or PI3K inhibitors. On the contrary, p-4E-BP1 expression levels prevailed in squamous cell carcinoma. Previous reports, however, assign eIF4E expression rather to lung adenocarcinomas, where it is thought to facilitate invasiveness $(48,49)$.

Among the molecules investigated, p-4E-BP1 immunoexpression levels increased in parallel with tumour status. The same applied to nuclear p-AKT expression as regards stage, whereas p-p70S6K (marginally) prevailed in low-grade/low T-category cases. A similar inverse correlation of marginal significance was observed between p-mTOR and histological grade. These findings concur with those of Liu et al (21) and advocate that the activation of mTOR and p70S6K appears more critical during the early stages of lung carcinogenesis as opposed to 4E-BP1 and AKT, which is a rather late event, contributing to the acquisition of a more aggressive phenotype. In harmony with our results, eIF4E overexpression was reportedly more prevalent in advanced stages of lung adenocarcinomas (25), whereas published data regarding the association of p-AKT and stage are controversial $(20,26)$. PTEN loss also marginally prevailed in high-grade cases, as in the study of Tang et al (20) and more importantly, the presence of the PTEN mutant genotype was associated with nodal metastases. A similar association, albeit of marginal significance, was obtained between the p110 $\gamma$ expression level and nodal status. The overall impression gained from these observations is the diverse role of $\mathrm{PI} 3 \mathrm{~K} / \mathrm{mTOR}$ signalling during the evolution of the neoplastic process in NSCLC.

One of the most significant findings emerging from the present study is the adverse prognostic significance of p-4E-BP1 expression in adenocarcinomas established in univariate analysis and remaining in multivariate analysis as a function of its interaction with p-AKT expression and histological type. p-AKT cytoplasmic expression on its own attained a marginal significance in univariate analysis in this regard. The survival time was also substantially shorter for patients with a co-expression of p-AKT and p-4E-BP1 than for those with either the single-positive or double-negative phenotype, implying that multi-targeted interventions may be more effective than the use of single inhibitors (21). For example, rapamycin has been shown to induce the phosphorylation of AKT and eIF4E, which was suppressed by a PI3K inhibitor (50). To the best of our knowledge, although there are a few studies investigating the prognostic significance of the PI3K/p-AKT/ mTOR pathway in NSCLC (18-23,26-32), the prognostic utility of $\mathrm{p}-4 \mathrm{E}-\mathrm{BP} 1$ expression in this regard has not been documented thus far.

The oncogenic effects of 4E-BP1 phosphorylation cannot be disentangled from those of eIF4E which coordinates translation initiation with the consequent preferential enhancement of the synthesis of growth-promoting or oncogenic proteins facilitating angiogenesis, invasion and metastasis. The strongest evidence supporting the role of the 4E-BP1/p-eIF4E interaction in NSCLC patient survival comes from 3 independent studies assigning a poor survival probability to p-eIF4E overexpression $(18,24,25)$ in lung adenocarcinomas. Current belief holds that the activation of 4E-BP1 represents the convergence point of several oncogenic pathways apart form mTOR, hence providing a better reflection of tumour aggressiveness than the upstream genetic alterations (51).

The prognostic role of the remaining components of the $\mathrm{PI} 3 \mathrm{~K} / \mathrm{AKT} / \mathrm{mTOR}$ pathway remains a controversial issue, with the majority of studies proposing p-AKT and/or (p-) mTOR as adverse $(18,20,21,28-32)$ and others as favourable $(19,26)$ prognosticators. The overexpression of p-p70S6K (or pS6) $(21,23)$, p85 or p110 subunits of PI3K (27), as well as PTEN loss (20) reportedly confer shorter survival. These inconsistencies may reflect the type of antibodies used (against phosphorylated or total molecules), quantification methods, variability in stage/ histology and the use of various cut-off points for categorization. It also becomes clear that not all components of the pathway have a similar impact on prognosis. Another issue 
that remains to be addressed is our inability to substantiate the prognostic value of stage in our series, which may be related to the fact that stages IIIB and IV were not represented.

In conclusion, in the present study, we provide evidence that alterations of the PI3K/AKT/mTOR pathway components are differentially implicated in the pathogenesis and aggressiveness of NSCLC. Our data stands in favour of nuclear p-4E-BP1 immunoexpression as a molecular marker of prognostic value in adenocarcinomas, particularly when combined with p-AKT. Careful evaluation of these parameters may help predict which tumours are most sensitive to PI3K/AKT signalling inhibitors (51).

\section{References}

1. Travis WD; IASLC Staging Committee: Reporting lung cancer pathology specimens. Impact of the anticipated 7th edition TNM classification based on recommendations of the IASLC Staging Committee. Histopathology 54: 3-11, 2009.

2. Jemal A, Siegel R, Ward E, et al: Cancer statistics: 2007. CA Cancer J Clin 57: 43-66, 2007.

3. Vivanco I and Sawyers CL: The phosphatidyloinositol 3-kinase AKT pathway in human cancer. Nat Rev Cancer 2: 489-501, 2002.

4. Sarbassov DD, Ali SM and Sabatini DM: Growing roles for the mTOR pathway. Curr Opin Cell Biol 17: 596-603, 2005.

5. Sarbassov DD, Ali SM, Kim DH, et al: Rictor, a novel binding pattern of mTOR, defines a rapamycin-insensitive and raptorindependent pathway that regulates the cytoskeleton. Curr Biol 14: 1296-1302, 2004.

6. Hay N and Sonenberg N: Upstream and downstream of mTOR Genes Dev 18: 1926-1945, 2004

7. Gingras AC, Gypi SP, Raught B, et al: Regulation of 4E-BP1 phosphorylation: a novel two-step mechanism. Genes Dev 13: 1422-1437, 1999.

8. Bjornsti MA and Houghton PJ: The TOR pathway: a target for cancer therapy. Nat Rev Cancer 4: 335-348, 2004.

9. Yu J, Zhang Y, McIlroy J, et al: Regulation of the p85/p110 phosphstidyloinositol 3'-kinase: stabilization and inhibition of the p110alpha catalytic subunit by the p85 regulatory subunit. Mol Cell Biol 18: 1379-1387, 1998.

10. Miled N, Yan Y, Hon WC, et al: Mechanism of two classes of cancer mutations in the phosphoinositide 3-kinase catalytic subunit. Science 317: 239-242, 2007.

11. Yamamoto H, Hisayuki S, Masaharu N, et al: PI3KCA mutations and copy number gains in human lung cancer. Cancer Res 68 693-621, 2008

12. Scrima M, De Marco C, Fabiani F, et al: Signaling networks associated with AKT activation in non-small cell lung cancer (NSCLC): new insights on the role of phosphatidyl-inositol-3 kinase. PLoS One 7: e30427, 2012.

13. Marti A and Felip E: PI3K pathway in NSCLC. Front Oncol 1: $55,2012$.

14. Stambolic V, Suzuki A, de la Pompa JL, et al: Negative regulation of PKB/Akt-dependent cell survival by the tumor suppressor PTEN. Cell 95: 29-39, 1998.

15. Wangpaichitr M, Wu C, You M, et al: Inhibition of mTOR restores cisplatin sensitivity through down-regulation of growth and anti-apoptotic proteins. Eur J Pharmacol 591: 124-127, 2008.

16. Balsara BR, Pei J,Mitsuuchi Y, et al: Frequent activation of AKT in non-small cell lung carcinomas and preneoplastic bronchial lesions. Carcinogenesis 25: 2053-2059, 2004.

17. Okudela K, Suzuki M, Kageyama S, et al: PIK3CA mutation and amplification in human lung cancer. Pathol Int 57: 664-671, 2007.

18. Yoshizawa A, Fukuoka J, Shimizu S, et al: Overexpression of phospho-eIF4E is associated with survival through AKT pathway in non-small cell lung cancer. Clin Cancer Res 16: 240-248, 2010

19. Anagnostou VK, Bepler G, Syrigos KN, et al: High expression of mammalian target of rapamycin is associated with better outcome for patients with early stage lung adenocarcinoma. Clin Cancer Res 15: 4157-4164, 2009

20. Tang JM, He QY, Guo RX, et al: Phosphorylated AKT overexpression and loss of PTEN expression in non-small cell lung cancer confers poor prognosis. Lung Cancer 51: 181-191, 2006.
21. Liu D, Huang Y, Chen B, et al: Activation of mammalian target of rapamycin pathway confers adverse outcome in nonsmall cell lung carcinoma. Cancer 117: 3763-3673, 2011.

22. Dobashi Y, Suzuki S, Matsubara H, et al: Critical and diverse involvement of $\mathrm{Akt} / \mathrm{mammalian}$ target of rapamycin signaling in human lung carcinomas. Cancer 115: 107-118, 2009.

23. McDonald JM,Pelloski CE,Ledoux A, et al: Elevated phospho-S6 expression is associated with metastasis in adenocarcinoma of the lung. Clin Cancer Res 14: 7832-7837, 2008.

24. Khoury T, Alrawi S, Ramnath N, et al: Eukaryotic initiation factor-4E and cyclin D1 expression associated with patient survival in lung cancer. Clin Lung Cancer 10: 58-66, 2009.

25. Wang R, Genng J, Wang JH, et al: Overexpression of eukaryotic initiation factor $4 \mathrm{E}$ (eIF4E) ad its clinical significance in lung adenocarcinoma. Lung Cancer 66: 237-244, 2009.

26. Oh MH, Lee HJ, Yoo SB, et al: Clinicopathological correlations of mTOR and pAkt expression in non-small cell lung cancer. Virchows Arch 460: 601-609, 2012.

27. Zito CR, Jilaveanu LB, Anagnostou V, et al: Multi-level targeting of the phosphatidyloinositol-3-kinase pathway in non-small cell lung cancer cells. PLoS One 7: e31331, 2012.

28. Gately K, Al-Alao B, Dhillon T, et al: Overexpression of the mammalian target of rapamycin (mTOR) and angioinvasion are poor prognostic factors in early stage NSCLC: a verification study. Lung Cancer 75: 217-222, 2012.

29. Dhillon T, Mauri FA, Belezza G, et al: Overexpression of the mammalian target of rapamycin: a novel biomarker for poor survival in resected early stage non-small cell lung cancer. J Thorac Oncol 5: 314-319, 2010.

30. Lim WT, Zhang WH, Miller CR, et al: PTEN and phosphorylated AKT expression and prognosis in early- and late-stage non-small cell lung cancer. Oncol Rep 17: 853-857, 2007.

31. Shi Y, Chen L, Li J, et al: Prognostic and predictive values of pERK1/2 and pAkt-1 expression in non-small cell lung cancer patients treated with adjuvant chemotherapy. Tumour Biol 32: 381-389, 2011.

32. David O, Jett J, LeBeau H, et al: Phospho-Akt overexpression in non-small cell lung cancer confers significant stage-independent survival disadvantage. Clin Cancer Res 10: 6865-6871, 2004.

33. Korkolopoulou P, Levidou G, Trigka EA, et al: A comprehensive immunohistochemical and molecular approach to the PI3K/AKT/ mTOR (phosphoinositide 3-kinase/v-akt murine thymoma viral oncogene/mammalian target of rapamycin) pathway in bladder urothelial carcinoma. BJU Int: E1237-E1248, 2012.

34. Levidou G, Saetta AA, Gigelou F, et al: ERK/pERK expression and B-raf mutations in colon adenocarcinomas: correlation with clinicopathological characteristics. World J Surg Oncol 10: 47, 2012.

35. Rojo F, Najera L, Lirola J, et al: 4E-binding protein 1, a cell signaling hallmark in breast cancer that correlates with pathologic grade and prognosis. Clin Cancer Res 13: 81-89, 2007.

36. Fujisaka Y, Yamada Y, Yamamoto N, et al: A phase 1 clinical study of temsirolimus (CCI-779) in Japanese patients with advanced solid tumors. Jpn J Clin Oncol 40: 732-738, 2010.

37. Pal SK, Figlin RA and Reckamp KL: The role of targeting mammalian target of rapamycin in lung cancer. Clin Lung Cancer 9: 340-345, 2008.

38. An SJ, Chen ZH, Su J, et al: Identification of enriched driver gene alterations in subgroups of non-small cell lung cancer patients based on histology and smoking status. PLoS One 7: e40109, 2012.

39. Thomas G: The S6 kinase signaling pathway in the control of development and growth. Biol Res 35: 305-313, 2002.

40. Riemenschneider MJ, Betensky RA, Pasedag SM, et al: AKT activation in human glioblastomas enhances proliferation via TSC1 and S6 kinase signaling. Cancer Res 66: 5618-5623, 2006.

41. Han S, Khuri FR and Roman J: Fibronectin stimulates non-small cell lung cancinoma cell growth through activation of Akt/ mammalian target of rapamycin/S6 kinase and inactivation of LKB1/AMP-activated protein kinase signal pathways. Cancer Res 66: 315-323, 2006

42. Johnson SM, Gulhati P, Rampy BA, et al: Novel expression patterns of $\mathrm{PI} 3 \mathrm{~K} / \mathrm{Akt} / \mathrm{mTOR}$ signaling pathway components in colorectal cancer. J Am Coll Surg 210: 767-778, 2010.

43. Bose S, Chandran S, Mirocha JM and Bose N: The Akt pathway in human breast cancer: a tissue-array-based analysis. Mod Pathol 19: 238-245, 2009.

44. Pantuck AJ, Seligson DB, Klatte T, et al: Prognostic relevance of the mTOR pathway in renal cell carcinoma: implications for molecular patient selection for targeted therapy. Cancer 109: 2257-2267, 2007 
45. Sun $\mathrm{CH}$, Chang $\mathrm{YH}$ and Pan CC: Activation of the PI3K/Akt/ mTOR pathway correlates with tumour progression and reduced survival in patients with urothelial carcinoma of the urinary bladder. Histopathology 58: 1054-1063, 2011.

46. Liliental J, Moon SY, Lesche R, et al: Genetic deletion of the Pten tumor suppressor gene promotes cell motility by activation of Rac1 and Cdc42 GTPases. Curr Biol 10: 401-404, 2000.

47. Dai B, Kong YY, Ye DW, et al: Activation of the mammalian target of rapamycin signaling pathway in prostate cancer and its association with patient clinicopathological characteristics. BJU Int 104: 1009-1016, 2009.

48. Seki N, Takasu T, Mandai K, et al: Expression of eukaryotic initiation factor $4 \mathrm{E}$ in atypical adenomatous hyperplasia and adenocarcinoma of the human peripheral lung. Clic Cancer Res 8: 3046-3053, 2002.
49. Rosenwald IB, Hutzler MJ, Wang S, et al: Expression of eukaryotic translation initiation factors $4 \mathrm{E}$ and 2 alpha is increased frequently in bronchioalveolar but not in squamous cell carcinomas of the lung. Cancer 92: 2164-2171, 2001.

50. Sun SY, Rosenberg LM, Wang X, et al: Activation of Akt and eIF4E survival pathways by rapamycin-mediated mammalian target of rapamycin inhibition. Cancer Res 65: 7052-7058, 2005.

51. Armengol G, Rojo F, Castellvi J, et al: 4E-binding protein 1 a key molecular 'funnel factor' in human cancer with clinical implications. Cancer Res 67: 7551-7555, 2007.

52. Dumstorf CA, Konicek BW, McNulty AM, et al: Modulation of 4E-BP1 function as a critical determinant of enzastaurin-induced apoptosis. Mol Cancer Ther 9: 3158-3163, 2010. 